UDK 614.841.45

https://doi.org/10.18485/fb_ic4hs.2018.17

\title{
EVACUATION CALCULATION AND MODELING: THE NEED FOR IMPROVING HUMAN LIVES SAFETY IN CASE OF FIRE
}

\author{
Mirjana LABAN*, Slobodan ŠUPIĆ ${ }^{* *}$, Suzana DRAGANIĆ ${ }^{* * *}$, Sanja MILANKO ${ }^{* * *}$
}

\begin{abstract}
One of the essential concepts of fire safety in buildings is the rapid and adequate evacuation of all the occupants of the building in case of fire. Many of the fire safety measures introduced in the design and operation of the building are aimed at ensuring that the occupants can safely leave the building before they are overtaken by heat and toxic products, and before the building collapses. Estimating the time required for evacuation is particularly important for buildings with large numbers of occupants, such as large residential, commercial and public buildings. The time required for the evacuation of all persons who could be present in the building when a fire occurs depends on a number of factors, some of which are very difficult to predict - for example, human behaviour. In our engineering practice, the calculation model is usually applied to determine the evacuation time. On the other hand, modelling and simulation are useful modern tools for the development of virtual scenarios and predictions and they are very important for obtaining dynamic information during an evacuation and identifying the critical points along the evacuation path. These evacuation models could help reduce the consequences of a wide range of adverse events, and can also be used for exploring how certain changes within the real system could affect the efficiency of evacuation and fire safety in a building even before they are implemented. A computer model of the Amphitheatres building in the Faculty of Technical Sciences in Novi Sad has been created using the Pathfinder simulation software, and the results of an experimental simulation of evacuation represent a basis for the assessment of safety in case of fire in public buildings with large numbers of occupants. A comparative analysis of the calculation and computer
\end{abstract}

\footnotetext{
* Associate Professor, PhD, University of Novi Sad, Faculty of Technical Sciences, Novi Sad, Serbia, mlaban@uns.ac.rs

** Teaching Assistant, MSc,_University of Novi Sad, Faculty of Technical Sciences, Novi Sad, Serbia, slobodansupic@gmail.com

${ }^{* * *}$ Assistant - master, University of Novi Sad, Faculty of Technical Sciences, Novi Sad, Serbia, suzanav@uns.ac.rs

${ }^{* * * *}$ BSc. Hon., MA Student / Disaster Risk Management and Fire Safety University of Novi Sad, Faculty of Technical Sciences, Novi Sad, Serbia, sanya6216@gmail.com
} 
model points to the need for future research and for the improvement of evacuation scenarios.

Keywords: evacuation, fire risk, simulation, modelling

\section{INTRODUCTION}

Over the last few decades, the understanding of human behaviour in fire has shifted away from the assumption that evacuees' responses are dominated by panic, (i.e., irrational and even self-destructive responses), and moved toward an acceptance of evacuees as adaptive and cooperative decision-makers sensitive to the information available (Kinsey et al., 2018). Several case studies (John Drury and Chris Cocking, 2007) have shown that, during mass emergency evacuations, there is rarely evidence of mass panic; behaviour is generally rational, mutual concern and help are common, and, there is evidence of a strong sense of shared social identity, especially amongst groups with some shared interests or affiliation. This new theory has had a significant impact on the area of fire safety design, influencing architectural/civil engineering design and enabling emergency planning and evacuation modelling.

Buildings are currently designed and constructed in accordance with prescriptive and performance-based methodologies to ensure the required level of safety. Prescriptive approaches rely on the application of a predetermined set of rules, such as simple engineering equations, used to determine the required safe egression time. These equations do not take into account evacuee behaviours (e.g. information seeking), or the factors influencing them, and make simplified assumptions regarding performance (Kuligowski et al., 2017). For example, the movement of the population is determined using the number of people in a space and the floor space available (area, distance, obstacles). These simplified assumptions may underestimate the time needed for a population to reach safety, possibly reducing design safety levels.

In contrast, performance-based designs rely on a quantitative assessment of the fire and the achieved evacuation performance levels. Over time, sophisticated computational tools have appeared. These tools can represent the evacuating population as individual agents and often more accurately represent the nature of the space and individual attributes. They also have the potential for representing factors that influence agent behaviour and agents' decision-making processes (such as pre-evacuation time, travel speed of different groups of people, width of evacuees' shoulders, social behaviour, etc.).

A case study of the Amphitheatres building at the Faculty of Technical Sciences (FTS) in Novi Sad and the results obtained by means of an experimental evacuation simulation could contribute to the fire risk assessment process in similar buildings. The evacuation time was determined using the Pathfinder simulation software based on the parameters defined by technical recommendations SRPS TP 21.

Future research on this subject would include examining the influence of walking speeds for different groups of people, including vulnerable groups, on evacuation time through evacuation exercises. This would lead to more accurate results on evacuees' behaviour and their walking speeds, as well as indicate the critical points along the evacuation corridor. 
The incorporation of these data into evacuation models would contribute to the validity of the models.

\section{BASIC DATA ON THE BUILDING}

When assessing the fire risk of buildings, it is necessary to take into account all the information relevant to fire protection, such as a building's infrastructure, the number of floors, its structural characteristics in terms of fire resistance, the purpose and content of the building, the applied fire protection measures, its distance from the fire brigade, etc.

The faculty of Technical Sciences is located in the central part of the University campus in Novi Sad, in Liman I city area. It consists of seven buildings and one of them, the Block of Amphitheatres, is the research subject of this paper (Fig. 1).

Access roads to the location from the professional firefighting rescue unit of Novi Sad are paved roads, of adequate width and capacity for firefighting vehicles. The travel distance of professional fire-rescue units to the location via the primary route is $4.2 \mathrm{~km}$, or the same distance in case of the alternative route (Fig. 2). The estimated time of arrival is seven minutes.

The Faculty is located on flat terrain; however, there is a depression in the Amphitheatre area so fire brigade interventions, in case of fire, have to be performed from a certain distance.

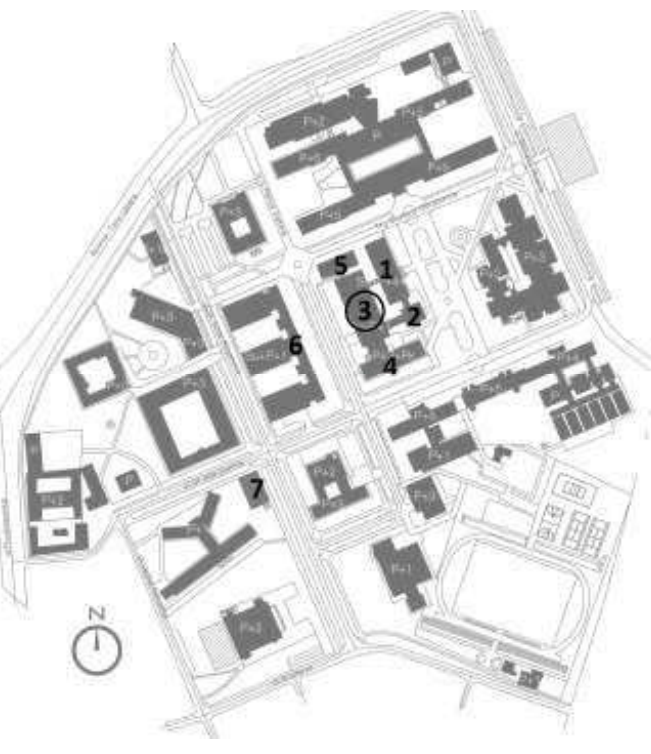

Fig. 1 University campus in Novi Sad: Location of buildings of FTS: 3- Amphitheatres

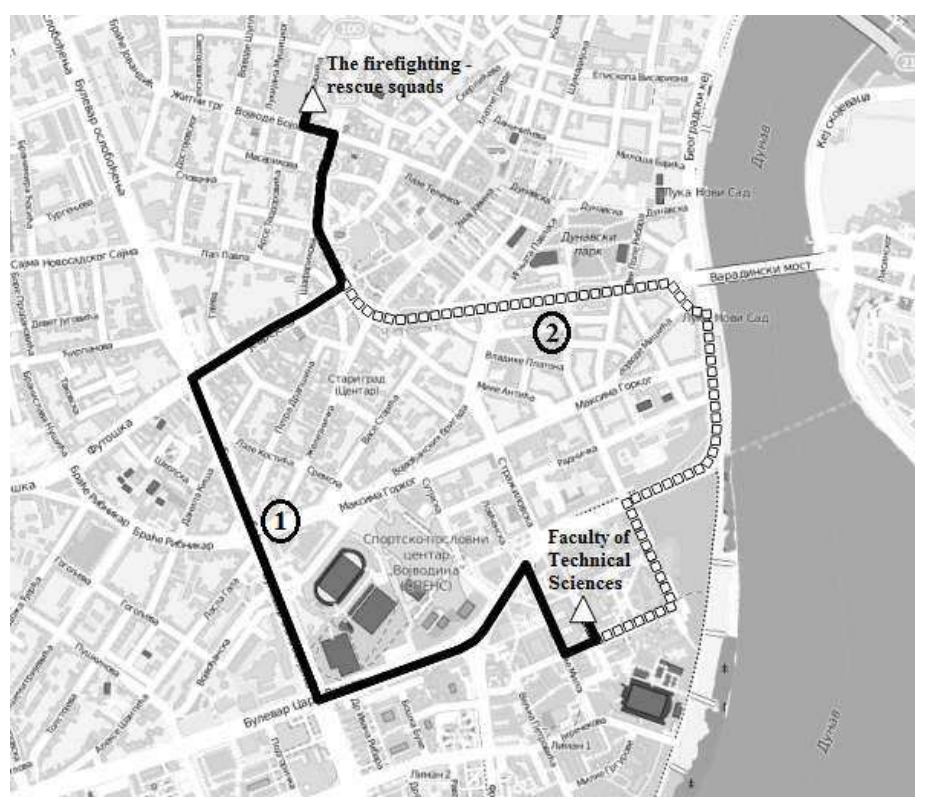

Fig. 2 Fire brigade's access roads to the location:

1-Primary route; 2-Alternative route;

FTS is a public building, which consists of a cellar, the ground floor and the first floor. As the height of the top floor does not exceed $30 \mathrm{~m}$ in relation to the surrounding ground, the building does not belong to the class of high-rise buildings. The main entrance (with a windshield) is from the Vladimir Peric Valter Street. The block of Amphitheatres is 
connected with the Administrative building, the Teaching block, ITC and Block F by pedestrian naccaoes (Fio 3$)$

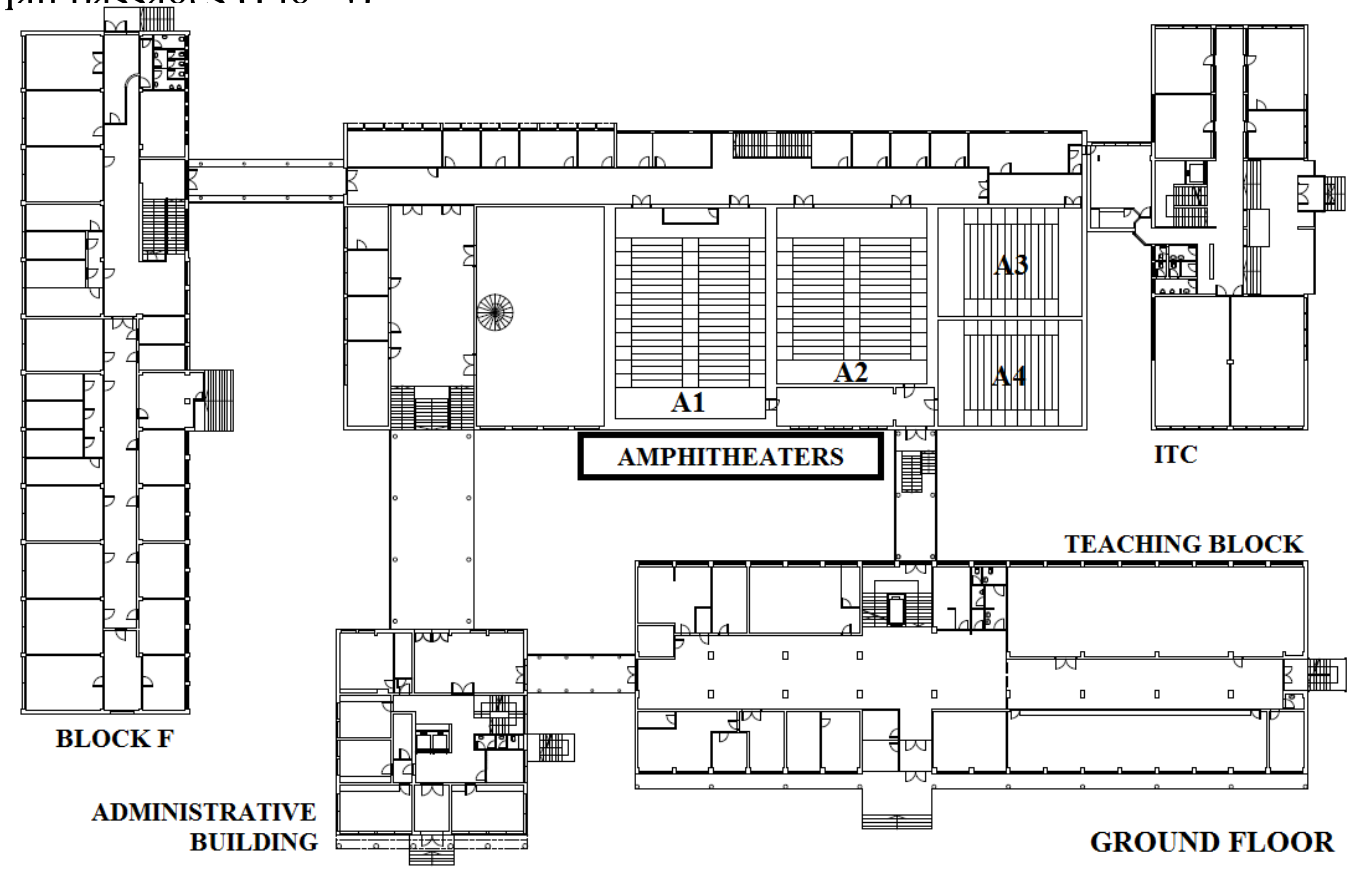

Fig. 3 Amphitheatres' connection to other FTS buildings

The load-bearing structure is made of reinforced concrete (henceforth: RC) and a RC canvas which serves to stiffen the structure. The exterior walls are plastered and made of brick. The roof is flat, impassable. Partition walls mainly consist of plastered and painted interior brick walls, although there are subsequently built partition walls made of plaster boards or lightweight wooden partitions. The windows and entrance portals are made of black metalwork with aluminium - strips and double glazing. The internal doors are wooden. The headroom is $345 \mathrm{~cm}$ high, while the maximum height in the amphitheatres is $740 \mathrm{~cm}$. The building's vertical communications consist of a three-way RC staircase positioned opposite the main entrance. The passages are made of RC, they are glazed and have a sufficient length to prevent the fire from spreading from one building to another. However, in case of a fire in this block, adjacent buildings would be endangered by smoke, so it is necessary to provide a full opening or breaking of glazed portals, to ensure smoke extraction from the evacuation routes and to prevent the spread of smoke through the related facilities. The corridors' floors are terrazzo floors or floors lined with marble slabs, while the floors in the amphitheatres, the library, the reading room, the classroom, the offices and cabinets are wooden floors or floors made of plastic materials. The walls are plastered and painted with dispersive colours. In the amphitheatres, the walls are partly covered with wooden boards. The floors and walls in the sanitary facilities have ceramic tiles. The ceilings are plastered and painted.

Aside from the four amphitheatres, a reception desk, a bookstore, a copy shop, a library, offices, storage rooms, a post office, a printing office and toilets are also located on the ground floor; a hall with exits from the amphitheatres and offices, a hall, a library, a copy shop, a bookstore, and offices are located on the first floor, and above the amphitheatres 
there is a classroom with a capacity for 30 people. The post office, printing office, bookstore and library have direct entrances / exits. The complete area of individual floors is approximately $2040 \mathrm{~m}^{2}$, while the total surface area is $3500 \mathrm{~m}^{2}$.

The maximum number of persons who could fit in the amphitheatres (mostly students) during a fire event or another event with catastrophic consequences is 830 , while the total number of people (with employees) who could be present in the building amounts to 1200 .

\section{SIMULATION SCENARIOS}

The evacuation simulation model was created using the Pathfinder simulation'software (Fig. 4).

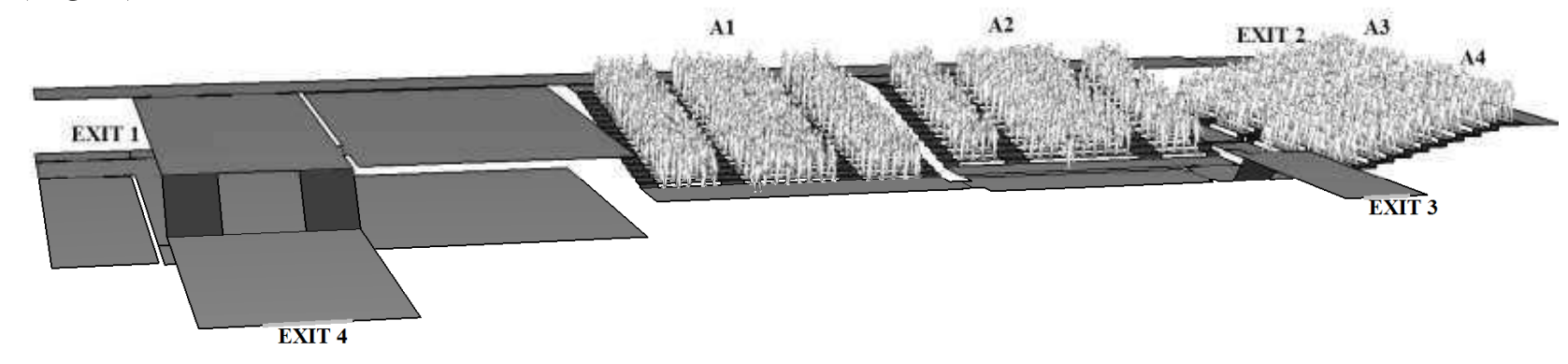

Fig. 4 Evacuation simulation model

The simulation scenarios were based on the layout of the building and the occupants' density in the case of a real fire incident. The walking speeds were defined using technical recommendations SRPS TP 21. The characteristics of the occupants (shoulder width, etc.) were randomized, in order to take into account different egress behaviours of different evacuees.

The scenarios foresee an evacuation where the occupants from all amphitheatres are being evacuated at the same time. The model includes the maximum number of people $-830-$ corresponding to the seating capacity. People from other buildings are not taken into account because it is unlikely that a fire will occur in all buildings at the same time.

All actors in the evacuation were assigned walking speeds in the interval between $1.2 \mathrm{~m} / \mathrm{s}$ and $1.5 \mathrm{~m} / \mathrm{s}$, where the walking speeds represent moving downstairs and the normal walking speed, respectively.

For the purpose of the research, three different scenarios were created, differing in terms of the actors' exit selection and undertaken fire safety measures.

\subsection{SIMULATION SCENARIO 1}

This simulation scenario is the worst case scenario in terms of the conditions. The occupants from the Amphitheatres A1 and A2 are evacuated through the upper exit doors, then through the hall on the ground floor level of the Block, down the stairs into the hall at the basement level, toward the main exit of the building (Exit 1) and to a safe place (Path 1).

The evacuation of the occupants from Amphitheatre A3 takes place from the amphitheatre's exit through the hall and the foyer connection with the building ITC (Exit 
2). ITC can be considered as a safe place if the opening in the wall that separates the two buildings is a fire- and smoke-proof door, and if we remove combustible materials from the passage. For now, this route is only the shortest escape route. The evacuation path leads through the passage to the ITC ground floor, down the staircase and into the hall to the main exit (Path 2). Due to the small capacity of the exit door of this communication, the escape route is not suitable for the evacuation of people from the other rooms of in the Amphitheatres block.

The evacuation of the occupants from Amphitheatre A4 is performed from the exit of the amphitheatre through the hall; up the stairs to the passage that connects this block with the Teaching Block, then through the hall and downstairs to the ground floor of the Teaching Block; and finally down the hall to the main entrance (Exit 3, Path 3). If for any reason this exit is inaccessible, it is possible to perform the evacuation by an alternative path from the landing of the main staircase downwards, towards the cellar and then through the hall to the Faculty's students' club and through the club outside.

\subsection{SIMULATION SCENARIO 2}

This simulation scenario represents the scenario closest to a real evacuation situation. It is realistic to expect that a number of the persons present will begin evacuating from Amphitheatres A1 and A2 through the lower exit doors, and their evacuation route is the same as the evacuation route of the occupants present in Amphitheatre A4 (Path 3). This scenario foresees an evacuation where one third of the actors use Path 3, while the other two thirds use Path 1 at the beginning of the evacuation until they arrive to the staircase. The actors then do not go down, but continue their evacuation through the passage leading through the Administrative Building to its exit (Exit 4). In this case, an unrestricted intervention of the fire brigade would be enabled as Exit 1 would be clear. Also, it can be expected that half of the occupants would instinctively follow the actors from A1 and A2.

\subsection{SIMULATION SCENARIO 3}

This simulation scenario represents the best case scenario in terms of the conditions, or an improved simulation scenario 1 . It is possible to significantly speed up the evacuation by opening a direct way out to the parking lot of the Faculty at basement level. In this case, everyone on the premises related to the ground floor corridor and the amphitheatres would be able to evacuate down the stairway connecting the two levels from the hallway and go outside directly. Also, opening an exit to the inner yard of the building would significantly unburden the escape route, i.e. Path 3.

In this scenario, one third of the occupants would evacuate from Amphitheatres A1 and A2 through the upper exit doors, through the hall and down the stairs leading to the newlyopened exit and out into the parking lot. One third of the occupants from these amphitheatres would take Path 1, while the other occupants from A1 would evacuate through the lower exit doors and then through the newly-opened exit to the inner yard of the building. Other A2 occupants, as well as the occupants from Amphitheatre A4 would take Path 3 during the evacuation. The occupants from Amphitheatre A3 would use Path 2 to reach the exit. 


\section{RESULTS DISCUSSION}

The total times (the average evacuation time obtained from 10 simulations) required to evacuate all persons from the amphitheatres, obtained using a computer model and based on the chosen simulation scenario are the following:

- Simulation scenario 1: $5 \mathrm{~min} .9 \mathrm{~s}$

- Simulation scenario 2: 4 min. $5 \mathrm{~s}$

- Simulation scenario 3: 3 min. 28s

Analysing the evacuation flow in simulation scenario 1, it can be noticed that while occupants are exiting through the upper amphitheatres' door, bottlenecks appear, as well as queues in the hall on the first floor (Fig. 5). This indicates the need for the disburdening of Path 1. The total time required for the evacuation of all persons, obtained in this scenario, amounts to 5 minutes 9 seconds.

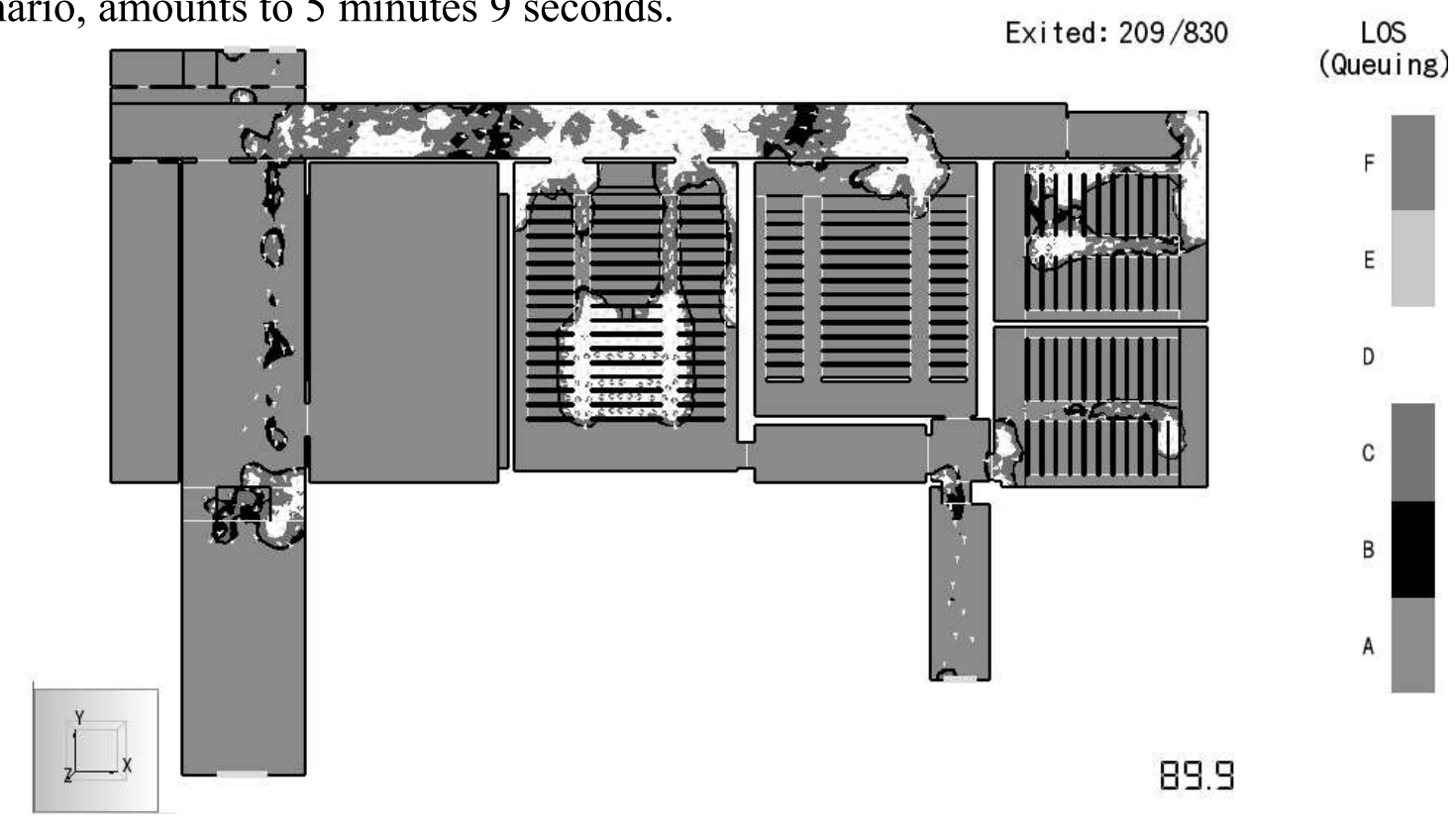

Fig. 5 Simulation scenario 1: Queuing of occupants in the hall above the amphitheatres

The implementation of the proper organizational measures predicted by simulation scenario 2 could reduce the evacuation time. This would require all employees to know their role in the fire event, to know who should try to extinguish the fire, who directs the human stream towards the evacuation exit, who directs people away from the building, etc. The total time required for the evacuation of all persons, obtained in this scenario, amounts to 4 minutes 5 seconds. If the doors are disburdened, it leads to the reduction of the evacuation time. There are still queues of people in the halls, but to a much lesser extent compared to the previous scenario (Fig. 6). 


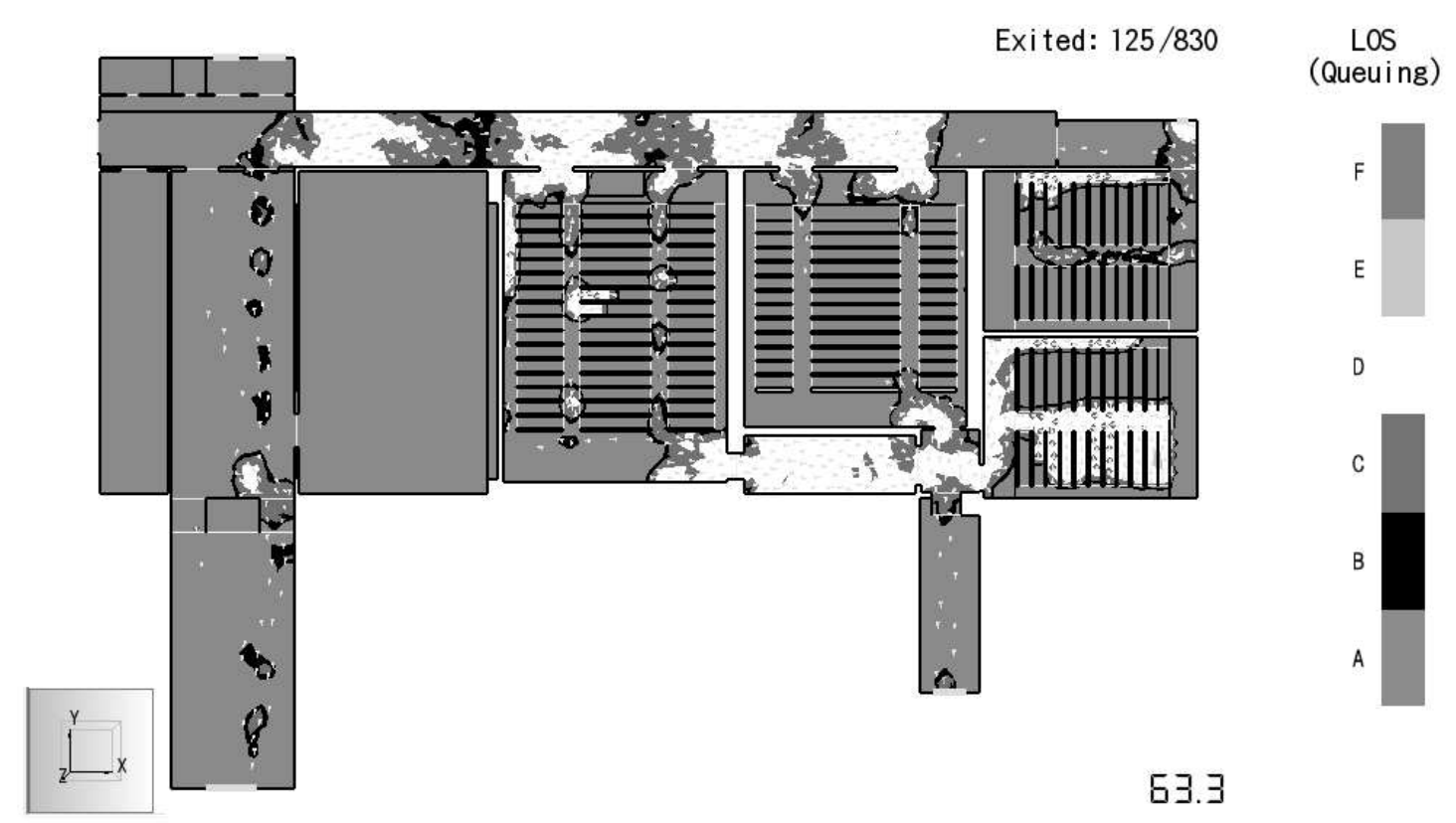

Fig. 6 Simulation scenario 2: Reduced evacuation time due to the disburdening of the doors

The implementation of the proper technical measures predicted by simulation scenario 3 could significantly reduce the evacuation time with regard to both previous scenarios. Opening a new exit door would also disburden the evacuation corridors (Fig. 7). This, of course, also requires the application of appropriate organizational measures. The total time required for the evacuation of all persons, obtained in this scenario, amounts to 3 minutes 28 seconds.

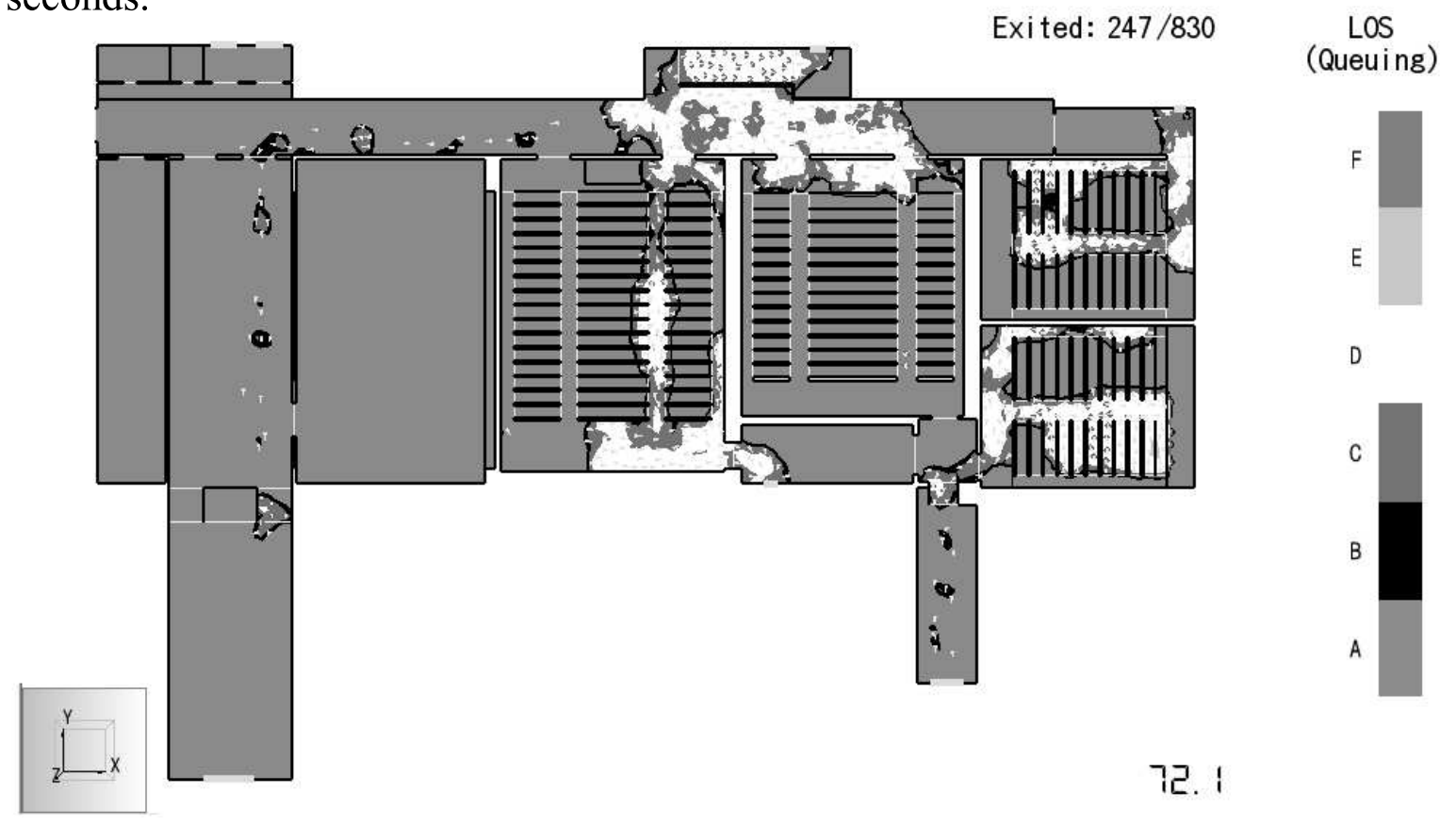

Fig. 7 Simulation scenario 3: Disburdening of the corridors and reduction of evacuation time by opening a new exit 


\section{CONCLUSIONS}

The time required for the evacuation of all persons who could be present in a building during a fire event depends on a number of factors. Many of them, including the nature of the space, the characteristics of the occupants (speed distribution, shoulder width, etc.), as well as their behaviour (social identity, exit choice etc.), are predictable, which enables evacuation modelling and the creation of different scenarios.

In this case study, three different scenarios were analysed: the worst-case scenario and another two scenarios as its improved versions gave the directions to act. Organizational measures - fire drills - should improve the occupants' awareness, and technical measures could improve the efficiency of the evacuation process.

Special attention should be paid to evacuation modelling involving vulnerable groups. The walking speeds of children, the elderly and people with disabilities differ from the usual walking speed (Long Shi et al., 2009). In order to ensure a safe evacuation, it is recommended that each member of these groups (evacuee) has an assigned person to take care of them during evacuation exercises.

In both of the improved versions of the simulation scenario the evacuation time was reduced. It leads us to the conclusion that, besides technical measures, education and regular drills for staff and students, training and preparing them for a real fire event would increase their chances of survival.

Simulation evacuation models enable the development and analysis of multiple scenarios of events. Based on these scenarios, adequate evacuation routes can be defined. This also goes for fire protection measures that could afterwards be implemented. Although these scenario simulations include major evacuation elements, such as: pre-evacuation time (the time for the evacuees to initiate response), physical movement characteristics (travel speed and flow conditions), route availability (the routes available to the evacuees), route usage/choice (the routes selected by the evacuees), they still represent the evacuee and the evacuee's decision-making in a grossly simplified form. In none of the existing evacuation models is the purposive evacuee decision-making process comprehensively represented. Thus, a comprehensive model of evacuees' decision-making and behaviour is required, which is left for future research.

\section{ACKNOWLEDGMENTS}

The paper presents part of the research realized in the project "Theoretical and experimental research and improvement of educational process in civil engineering" conducted by the Department of Civil Engineering and Geodesy, Faculty of Technical Sciences, University of Novi Sad.

\section{REFERENCES}

Erica D. Kuligowski, Steven M. V. Gwynne, Michael J. Kinsey, Lynn Hulse - Guidance for the Model User on Representing Human Behavior in Egress Models, Fire Technology, 2017 
John Drury and Chris Cocking - The mass psychology of disasters and emergency evacuations: A research report and implications for practice, University of Sussex, 2007.

M. J. Kinsey, S. M. V. Gwynne, E. D. Kuligowski, M. Kinateder - Cognitive Biases Within Decision Making During Fire Evacuations, Fire Technology, 2018.

SRPS TP 21: Technical recommendations for urban and civil engineering measures of fire safety for residential, commercial and public buildings, 2003, Belgrade, Serbia

Long Shi, Qiyuan Xie, Xudong Cheng, Long Chen, Yong Zhou, Ruifang Zhang Developing a database for emergency evacuation model, Building and Environment 44, 2009 